\title{
BMJ Open Prevalence and temporal trends of presarcopenia metrics and related body composition measurements from the 1999 to 2006 NHANES
}

\author{
Ji-Bin Li (D) , ${ }^{1}$ Yuwan $\mathrm{Wu},{ }^{2}$ Dantong Gu, ${ }^{3}$ Huajun $\mathrm{Li},{ }^{2}$ Xi Zhang (D) ${ }^{4}$
}

To cite: Li J-B, Wu Y, Gu D, et al. Prevalence and temporal trends of presarcopenia metrics and related body composition measurements from the 1999 to 2006 NHANES. BMJ Open 2020;10:e034495. doi:10.1136/ bmjopen-2019-034495

- Prepublication history for this paper is available online. To view these files, please visit the journal online (http://dx.doi. org/10.1136/bmjopen-2019034495).

Received 28 September 2019

Revised 06 June 2020

Accepted 25 June 2020

Check for updates

(C) Author(s) (or their employer(s)) 2020. Re-use permitted under CC BY-NC. No commercial re-use. See rights and permissions. Published by BMJ.

${ }^{1}$ Department of Clinical

Research, Sun Yat-sen University Cancer Center, Guangzhou,

China

${ }^{2}$ Department of Pediatrics, Xinhua Hospital Affiliated to Shanghai Jiaotong University School of Medicine, Shanghai, China

${ }^{3}$ Department of Bio-statistics, Fudan University School of

Public Health, Shanghai, China ${ }^{4}$ Clinical Research Unit, Xinhua Hospital Affiliated to Shanghai Jiaotong University School of Medicine, Shanghai, China

Correspondence to Dr Xi Zhang; zhangxi@xinhuamed.com. cn and

Dr Huajun Li;

lihuajun@xinhuamed.com.cn

\section{ABSTRACT}

Objective To evaluate the prevalence and temporal trends of presarcopenia and related body composition measurements.

Design Cross-sectional study.

Setting National Health and Nutrition Examination Survey (NHANES) 1999-2006.

Methods Presarcopenia was defined according to the guidelines from the European Working Group on Sarcopenia. Logistic or linear regression models were used to evaluate the linear trend of the prevalence of presarcopenia, obesity and related body composition measurements.

Participants A total of 29947 participants aged 18-90 years from five waves of the NHANES were included in the analysis.

Outcome measures Presarcopenia was sex-specifically defined as having a skeletal mass index $\leq 7.26 \mathrm{~kg} / \mathrm{m}^{2}$ in men and $\leq 5.5 \mathrm{~kg} / \mathrm{m}^{2}$ in women. Body composition measurements, including total body fat percentage, total body fat mass, total lean body mass, appendicular skeletal muscle mass and bone mineral density, were obtained by dual-energy X-ray absorptiometry.

Results The overall prevalence of presarcopenia ranged from $16.4 \%$ in $1999-2000$ to $14.8 \%$ in $2005-2006$ (p for trend=0.78). Presarcopenia was stable in both males ( $p$ for trend $=0.36$ ) and females ( $p$ for trend $=0.20$ ). The presarcopenia prevalence was significantly elevated among the age group of $18-39$ years old (from $11.3 \%$ to $14.1 \%, p$ for trend $=0.04$ ) and among non-Hispanic blacks ( $p$ for trend $<0.001$ ). Adults aged $\geq 80$ years old had the highest prevalence.

Conclusions The prevalence of presarcopenia increased among young individuals over time. Non-Hispanic blacks also demonstrated an increasing trend in the prevalence over time.

\section{INTRODUCTION}

According to the 2010 European Working Group on Sarcopenia in Older People (EWGSOP), sarcopenia is defined as a cluster of geriatric conditions characterised by progressive and generalised loss of skeletal muscle mass and strength with a high risk of adverse outcomes, including poor quality of life, physical disability and even death. ${ }^{1}$ The
Strengths and limitations of this study

- We used the data from the nationally representative population-based surveys of the National Health and Nutrition Examination Survey (1999-2006).

- Body composition measurements were obtained by the gold-standard dual energy $X$-ray absorptiometry.

- Appendicular skeletal muscle mass rather than muscle strength and physical performance was assessed.

- The prevalence of presarcopenia in women may be underestimated when using a height-adjusted definition of presarcopenia.

- Reporting bias may exist due to self-reported physical activity data.

prevalence of presarcopenia $(5.9 \%)$ and sarcopenia $(4.4 \%)$ among adults aged 45 years and older is high in the Netherlands. ${ }^{2}$ It has been conservatively estimated that sarcopenia affects more than 50 million people around the world and will increase by more than 200 million over the next 40 years. ${ }^{3}$

Currently, there are a variety of definitions for sarcopenia, none of which have been agreed on, and the prevalence of the disease is highly dependent on the diagnostic criteria used. Among the three components of sarcopenia defined in the EWGSOP, muscle mass, muscle strength and performance, muscle mass plays a critical role in the progression of sarcopenia, and low muscle mass has been identified as presarcopenia. Sarcopenia, especially in the context low skeletal muscle mass, is mainly caused by ageing, decreased participation in physical activities, ${ }^{4}$ malnutrition $^{56}$ and endocrine and metabolic disorders. ${ }^{7}$ These factors directly contribute to the loss of muscle mass, ${ }^{8}$ influencing muscle strength and performance and leading to a lower metabolic rate and reduced physical activity, which often causes fat gain. The gained fat could lead to a further loss of 
muscle mass and strength via cytokine protein catabolism ${ }^{9}$ and insulin resistance. ${ }^{10}$ Thus, sarcopenia and its effects can be part of a spiralling process of declining health.

Sarcopenic obesity, defined as a loss in body lean mass but preservation or even an increase in body fat mass, can have serious health implications. Recent data have indicated that obesity affects more people of younger age due to physical inactivity. ${ }^{11}$ Therefore, it is reasonable to hypothesise that the prevalence of presarcopenia has increased accordingly. Currently, there is a lack of evidence to support this statement. Numerous studies have reported that sarcopenia/low muscle mass is related to frailty, ${ }^{12}$ inflammation, ${ }^{13}{ }^{14}$ liver fibrosis, ${ }^{15} 16$ cirrhosis, ${ }^{17} 18$ systemic sclerosis, ${ }^{19}$ cancer, ${ }^{20-22}$ chronic obstructive pulmonary disease, ${ }^{23}$ cardiovascular disease, ${ }^{24}{ }^{25}$ and mortality, ${ }^{26}$ all of which place considerable health and economic burdens on public healthcare services. Thus, it is important to depict the prevalence and temporal trends of presarcopenia and related body composition measurements over time in relation to sex, age and race to better inform public health policy and prevention strategies.

In this study, we estimated the population-based prevalence and temporal trends of presarcopenia metrics and related body composition measurements among adults in the USA from 1999 to 2006 by using data from the National Health and Nutrition Examination Survey (NHANES).

\section{METHODS}

\section{Study design and participants}

The NHANES is a nationally representative cross-sectional survey among non-institutionalised civilians in the USA. ${ }^{27}$ This analytical study involved participants aged 18 years and older from the NHANES cohort surveyed across four consecutive cycles: 1999-2000 ( $n=3559), 2001-2002$ $(n=4047), 2003-2004(n=3771)$ and 2005-2006 $(n=3071)$. All participants provided written informed consent.

\section{Body component measurements and presarcopenia}

Physical examinations were conducted in mobile examination centres. Weight in kilograms, height in centimetres and waist circumference (WC) in centimetres were measured using standardised techniques and equipment. Body mass index (BMI) was calculated as weight in kilograms divided by the square of the height in metres. Overweight was defined as a BMI between 25.0-29.9 and obesity as a BMI of 30.0 or higher. ${ }^{28}$ Central obesity was defined as having a WC of $>102 \mathrm{~cm}$ for males and $>88 \mathrm{~cm}$ for females. ${ }^{29}$ Total body fat percentage, total body fat mass, total lean body mass, appendicular skeletal muscle mass (ASM) and bone mineral density (BMD) were measured using dual-energy X-ray absorptiometry (DXA) in the four surveys from 1999 to 2006. The total ASM (TASM) mass index was calculated as the ASM divided by the height squared $\left(\mathrm{kg} / \mathrm{m}^{2}\right)$. Presarcopenia was sexspecifically defined as having a TASM $\leq 7.26 \mathrm{~kg} / \mathrm{m}^{2}$ in men and $\leq 5.5 \mathrm{~kg} / \mathrm{m}^{2}$ in women. ${ }^{30}$

\section{Physical activity and socialdemographic factors}

Participants' sex, age, race, education level, annual household income, time spent watching television (TV) per day and level of physical activity were collected by household interviews. Age was grouped into three categories: 18-39 years old, 40-59 years old and 60 years or older. Race was classified as non-Hispanic white, nonHispanic black, Mexican American and others. Educational level was categorised into $<$ high school graduate, high school graduate/general equivalency diploma or $\geq$ college. Time spent watching TV per day was grouped into $<2$ hours, $2-4$ hours or $>4$ hours. Annual household income was grouped into <US\$25 000, US\$25 000-US\$55 000 or $>$ US $\$ 55000$. Physical activity was grouped into two levels: moderate/below or vigorous.

\section{Statistical analyses}

Participants' characteristics, including sex, age, race, education level, annual household income, time spent watching TV per day and level of physical activity, are shown as unweighted frequencies and weighted percentages with $95 \%$ CIs. Weighted means and corresponding 95\% CIs of body weight, BMI and obesity, WC and central obesity, total body fat percentage, total lean body mass, ASM, TASM and BMD were calculated, and mean changes with $95 \%$ CIs of all these variables from 1999-2000 to 2005-2006 were calculated.

The age-adjusted and sex-adjusted prevalence of presarcopenia was calculated for the four survey cycles from 1999-2000 to 2005-2006 for the overall sample and the sex, age, race, education level, annual household income, time spent watching TV per day and physical activity level subgroups. The temporal trends of presarcopenia prevalence, obesity and different body composition measurements, including TASM, WC, BMD and total percentage of body fat (TPF), for the overall sample and within the subgroups were assessed by survey-weighted linear (for continuous outcomes) or logistic (for binary outcomes) regression models with survey year as a continuous (ordered categorical) independent variable after adjustment for sex, age, race, education level, annual household income, time spent watching TV per day and physical activity level. ${ }^{31} 32$

Sampling weights were used to account for unequal probabilities of selection and non-responses for all analyses, thereby providing estimates representative of the non-institutionalised civilian US population. All statistical analyses were performed using SAS for Windows V.9.4 (SAS Institute). A two-sided $\mathrm{p}<0.05$ was considered statistically significant.

\section{Patient and public involvement}

There was no patient or public involvement in this study.

\section{RESULTS}

A total of 14448 participants were included in this study, with 3559 from 1999 to 2000, 4047 from 2001 to 2002, 3771 from 2003 to 2004 and 3071 from 2005 to 2006 
స్్ㅐ

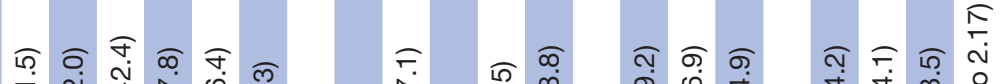
in

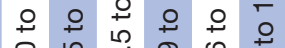
일 过过过过安它 र ल क क ल

8

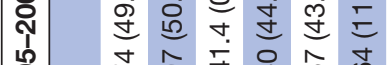

岗 究

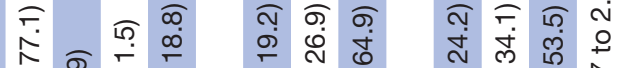

○

ᄃㅇำ

迎 它

न के क

E ह

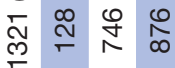

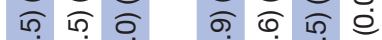

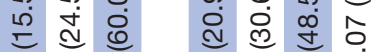

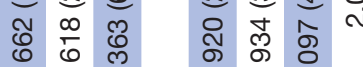

E ูำ
งุ

盛

우 우 오

$\infty$. 0.9

로

in $\widehat{\infty}$

ปู

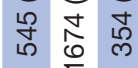

$\widehat{0} \overline{0}$

กิ

का

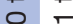

हூ

i

लं लें

क्षै ले

क्ष लं ब्ले

๕

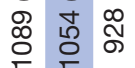

I

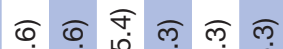

疋

II

ชั

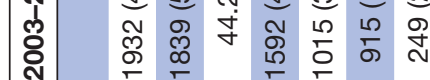

赵

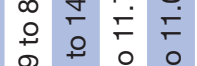

ค․

e)

लู

든

난
T)

ลิ่

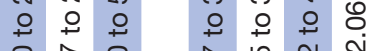

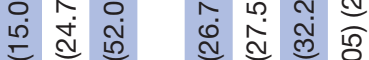

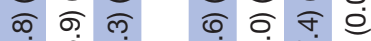

芒

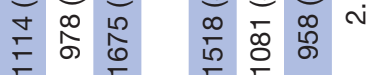

क ปे

앙ㅇㅇㅇ

ก. เก

든을

o र ल

ูำ

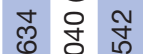

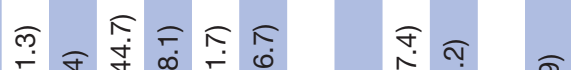

i

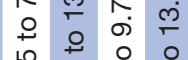

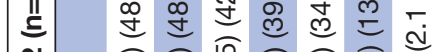

先

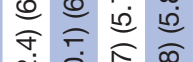

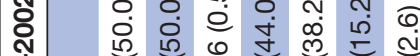

슨을

玄

范

ํ.

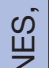

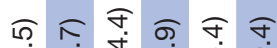

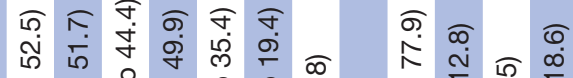

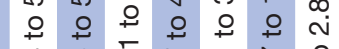

․

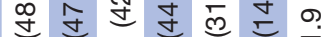

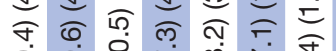

造守

న్

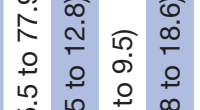

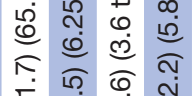

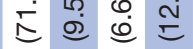

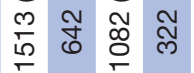

จ $T$ ल क

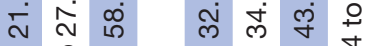

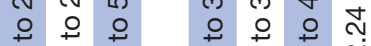

ㅇ. $\%$

돌 通

สุ ธิ ल

둔

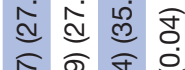

ํํㄹ ผ

임

बiे वें क्ल

告离

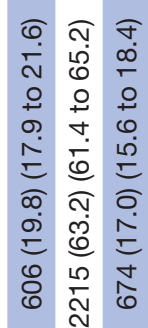

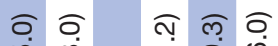

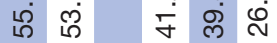

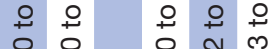

辛守

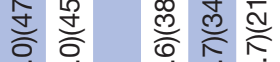

逭守

ल्र

崩

रิช

ஸें

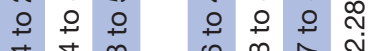

ナ.

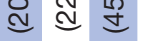

ฮิ

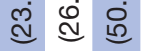

亲

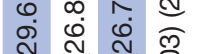

त क

iी कृ ल्ले ले

ปิ
बढ

त

$+\circ$ 우

N̂용

เก ल สุ

คำ

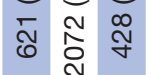

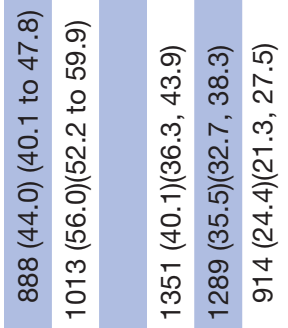

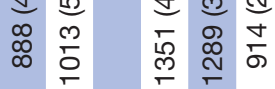

$\overline{\mathrm{c}}$

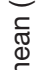

ธิ

ओे

कृ

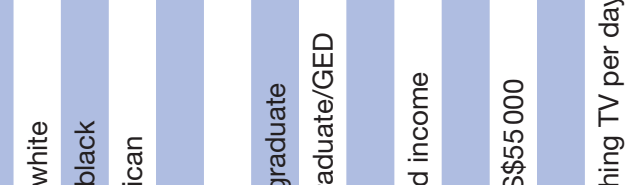

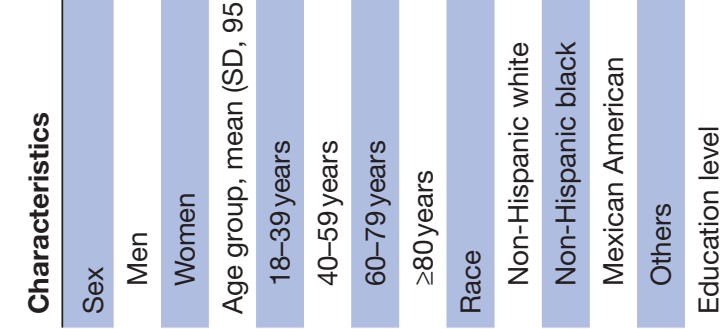

$\frac{2}{2} \frac{0}{2}$

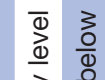

สิ 它

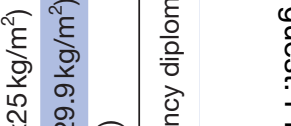

0
$\frac{0}{0}$
$\frac{1}{0}$
$\frac{0}{10}$
$\frac{2}{0}$
$\frac{9}{2}$
8
$\frac{8}{0}$
$\frac{1}{2}$
$\frac{1}{7}$ 


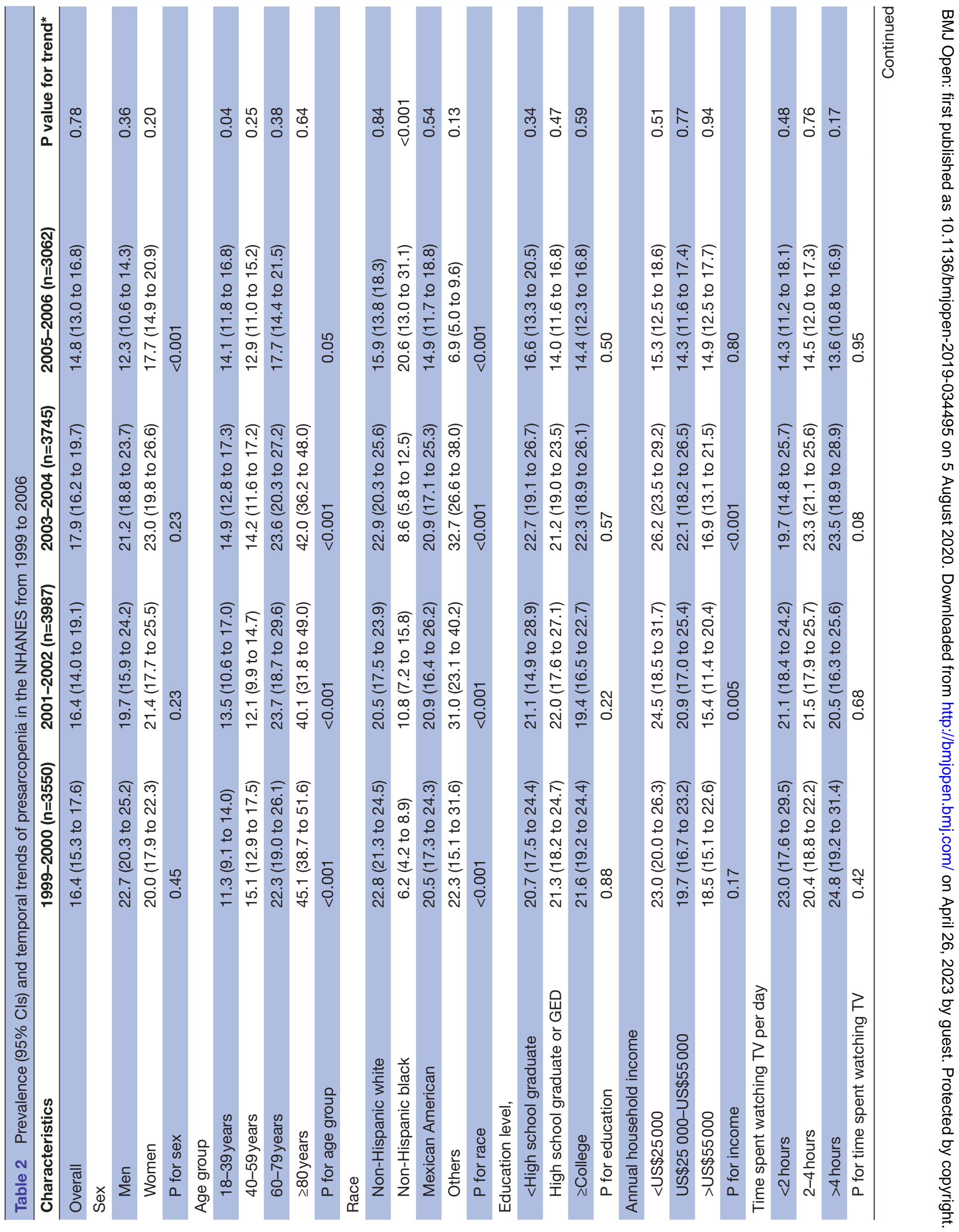




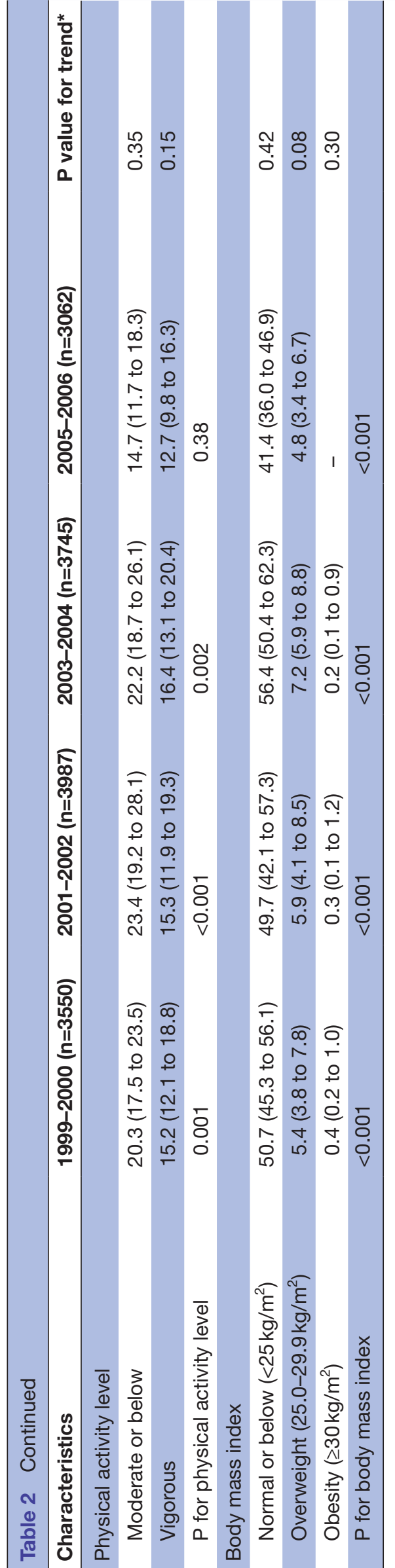

(table 1). The distributions of the participants' characteristics across the four survey cycles were comparable. In $1999-2000,49.6 \%$ of the participants were women, $19.5 \%$ were 60 years or older, and $71.7 \%$ were non-Hispanic white. The proportion of patients with a vigorous physical activity level showed a significantly decreasing trend from 1999 to $2006(\mathrm{p}<0.001)$.

\section{Prevalence and temporal trends of presarcopenia from 1999 to 2006}

The overall age-adjusted and sex-adjusted prevalence of presarcopenia ranged from $16.4 \%$ (95\% CI $15.3 \%$ to $17.6 \%$ ) in $1999-2000$ to $14.8 \%$ (95\% CI $13.0 \%$ to $16.8 \%$ ) in 2005-2006 ( $\mathrm{p}$ for trend $=0.78$ ) (table 2).

The age-adjusted prevalence of presarcopenia in men was $22.7 \%$ (95\% CI $20.3 \%$ to $25.2 \%$ ) in $1999-2000$ and $12.3 \%$ (95\% CI $10.6 \%$ to $14.3 \%$ ) in $2005-2006$ (p for trend $=0.36$ ), while in women, the prevalence was $20.0 \%$ in 1999-2000 and $17.7 \%$ in 2005-2006 ( $P$ for trend $=0.20$ ). The prevalence of presarcopenia in women was significantly higher than that in men in 2005-2006 (17.7\% for women vs $12.3 \%$ for men; $\mathrm{p}<0.001)$. There were also racial differences in presarcopenia prevalence as well as temporal trends. The prevalence significantly increased from $6.2 \%$ in $1999-2000$ to $20.6 \%$ in $2005-2006$ among non-Hispanic blacks ( $\mathrm{p}$ for trend $<0.001$ ) but remained stable among non-Hispanic whites $(\mathrm{p}$ for trend $=0.84$ ) and Mexican Americans ( $p$ for trend=0.54) from 1999 to 2006. Compared with those in the other age groups, participants aged $\geq 80$ years and $60-79$ years had a significantly higher prevalence of pre-sarcopenia in the four survey cycles from 1999 to 2006. In three of the survey cycles (1999-2000, 2001-2002 and 2003-2004), compared with those who reported moderate/low physical activity levels, participants who reported vigorous physical activity levels were more likely to have a lower prevalence of presarcopenia $(p<0.001)$. In addition, participants with higher annual household incomes had a lower prevalence of presarcopenia in the 2001-2002 and 2003-2004 survey cycles. In all four survey cycles, participants with BMI $<25 \mathrm{~kg} / \mathrm{m}^{2}$ had a relatively higher prevalence of presarcopenia than overweight and obese participants.

\section{Body composition measurements}

The average body weight across all participants significantly increased from $76.8 \mathrm{~kg}$ (95\% CI 75.6 to 77.9$)$ in $1999-2000$ to $78.9 \mathrm{~kg}$ (95\% CI 77.4 to 80.4 ) in 2005-2006 ( $\mathrm{p}$ for trend=0.010), with an average increase of $2.11 \mathrm{~kg}$ (95\% CI 0.28 to $3.93 \mathrm{~kg}$ ) (table 3 ). Correspondingly, the prevalence of obesity significantly increased from $24.3 \%$ (95\% CI $21.2 \%$ to $27.4 \%$ ) to $29.3 \%$ (95\% CI $25.8 \%$ to $32.7 \%$ ) in the overall population ( $\mathrm{p}$ for trend $=0.023$ ) and from $20.8 \%$ (95\% CI $17.9 \%$ to $23.7 \%$ ) to $27.6 \%$ (95\% CI $23.0 \%$ to $32.1 \%$ ) in men ( $p$ for trend $=0.007$ ) but remained stable in women (from $28.0 \%$ to $30.9 \%$, p for trend $=0.229$ ) over time (table 3 and figure 1A). After stratification by age (figure 1B), the prevalence of obesity significantly increased from $25.6 \%$ to $33.8 \%$ in the $40-59$ 


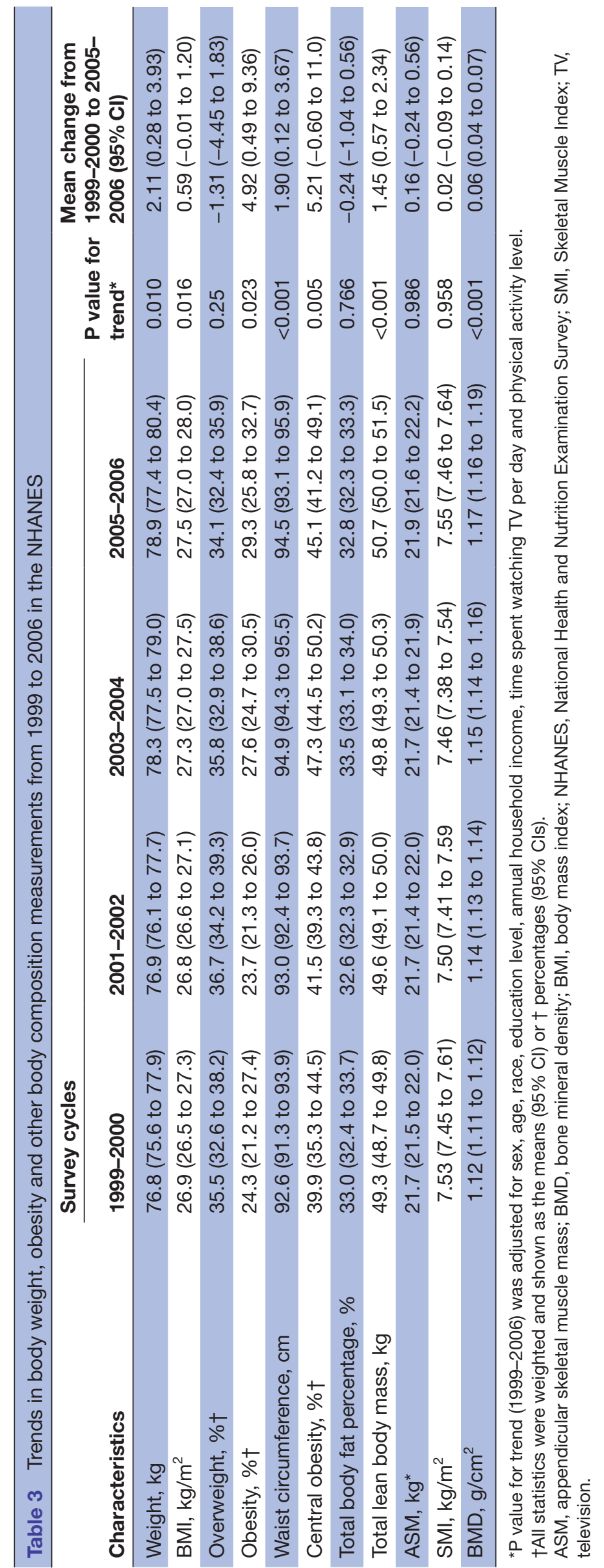




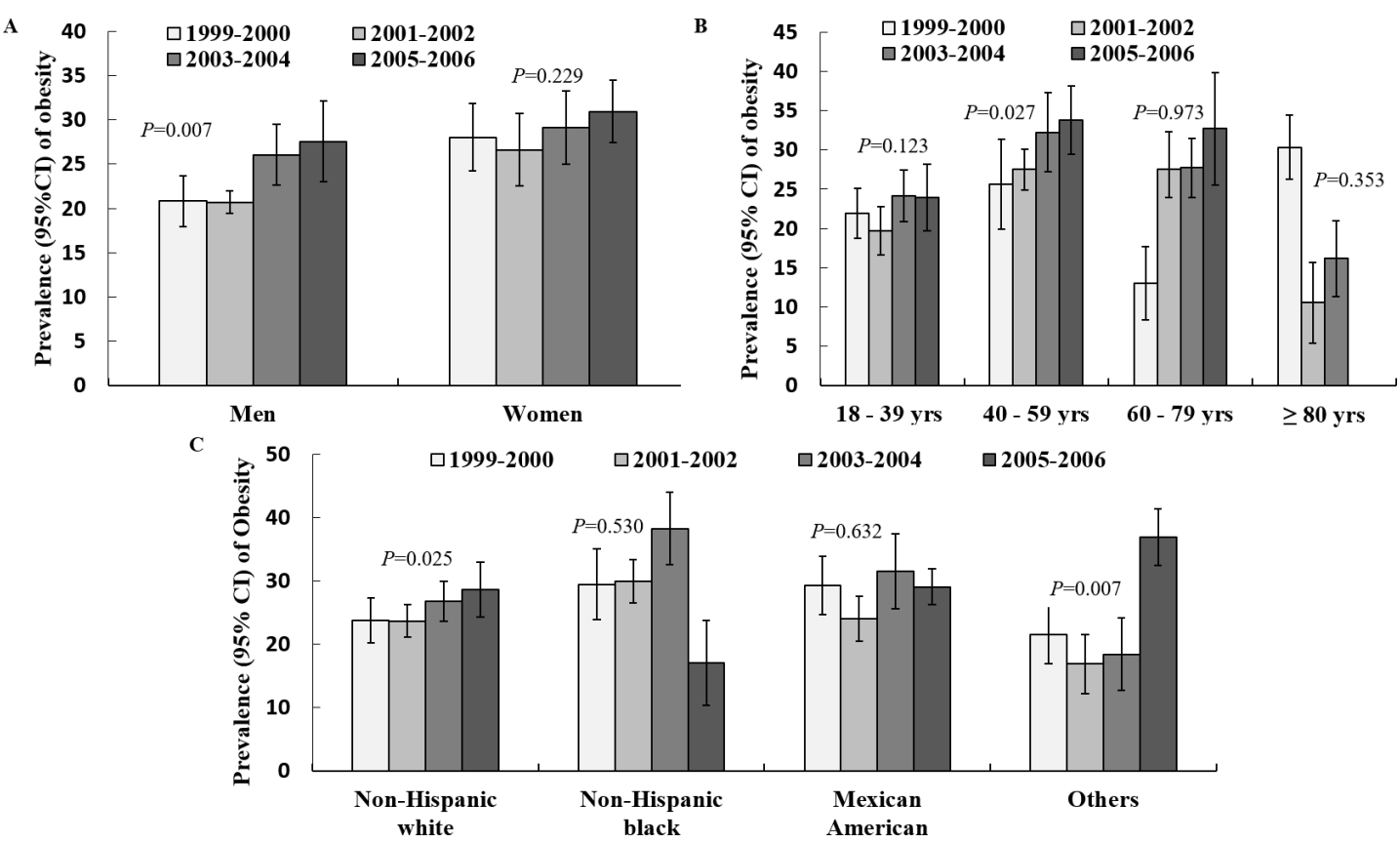

Figure 1 Prevalence of obesity stratified by sex (A), age (B) and racial group (C) from 1999 to 2006 in the NHANES. 95\% Cl. $\mathrm{P}$ values refer to temporal trends obtained by logistic regression models after adjusting for sex, age, race, education level, annual household income, time spent watching TV per day and physical activity level. NHANES, National Health and Nutrition Examination Survey; TV, television.

age group ( $\mathrm{p}$ for trend $=0.027$ ) but remained stable in the other three age groups. Similar increasing trends of obesity prevalence were observed in non-Hispanic whites (from $23.8 \%$ to $28.6 \%$, $p$ for trend=0.025) but were statistically stable in non-Hispanic blacks and Mexican Americans (figure 1C). From 1999 to 2006, the TASM significantly decreased in the non-Hispanic black group but significantly increased in the Mexican American and other ethnic groups (table 3 and figure 2A). Meanwhile, we observed a slight increase in WC (table 3 and figure 2B), total lean body mass (table 3 ), prevalence of central obesity (table 3 ) and BMD (table 3 and figure 2C), however, we did not detect any significant trends for TPF (figure 2D).

\section{DISCUSSION}

In this large-scale study that analysed nationally representative data from US respondents to the NHANES, we found that the overall prevalence of presarcopenia remained stable, while there was a substantial increase in the prevalence for the non-Hispanic black and young age groups from 1999 to 2006 . Hence, our hypothesis regarding an increasing trend in the presarcopenia prevalence over time was not fully supported by the findings. Our results indicate that certain subpopulations might be more vulnerable to pre-sarcopenia than the overall population. Indeed, we found that individuals who were older or under/normal weight had a considerably higher prevalence of presarcopenia.

Our study found an increasing trend in the prevalence of obesity and central obesity from 1999 to 2006 among the overall population. Previous studies reported that obesity can lead to loss of muscle mass and strength ${ }^{33}$ and is commonly accompanied by a reduction in physical activity and deterioration of metabolic disorders, which in turn accelerates the abnormal distribution of fat mass and initiates the process of sarcopenia. ${ }^{34}$ In contrast, it is interesting that the prevalence of presarcopenia was considerably higher in under/normal weight adults than in obese adults in our study. The contradictory findings might be explained by the fact that our study only measured skeletal muscle mass, but the muscle mass of under/normal weight individuals might be relatively lower than that of overweight/obese individuals. In addition, our study focused on presarcopenia rather than sarcopenia, which is defined as the presence of both low muscle mass and low muscle function (strength or physical performance).

A previous study reported that skeletal muscle mass begins to decrease at approximately 30-39 years old. ${ }^{35}$ Accordingly, we found a relatively higher prevalence of presarcopenia in the older age groups than in the 18-39 age group. However, it is still unclear whether muscle mass reduction would further accelerate muscle strength loss and ageing-related health issues. Observational studies have reported a linearly positive association between muscle mass and strength in both middle-aged and elderly people. ${ }^{36-38}$ This indicates that the amount of muscle mass acquired during youth may protect adults from the early onset of sarcopenia. Therefore, it may be beneficial to pay more attention to increasing muscle mass in both young and old populations. The peak period of muscle strength lags nearly 10 years behind the peak 

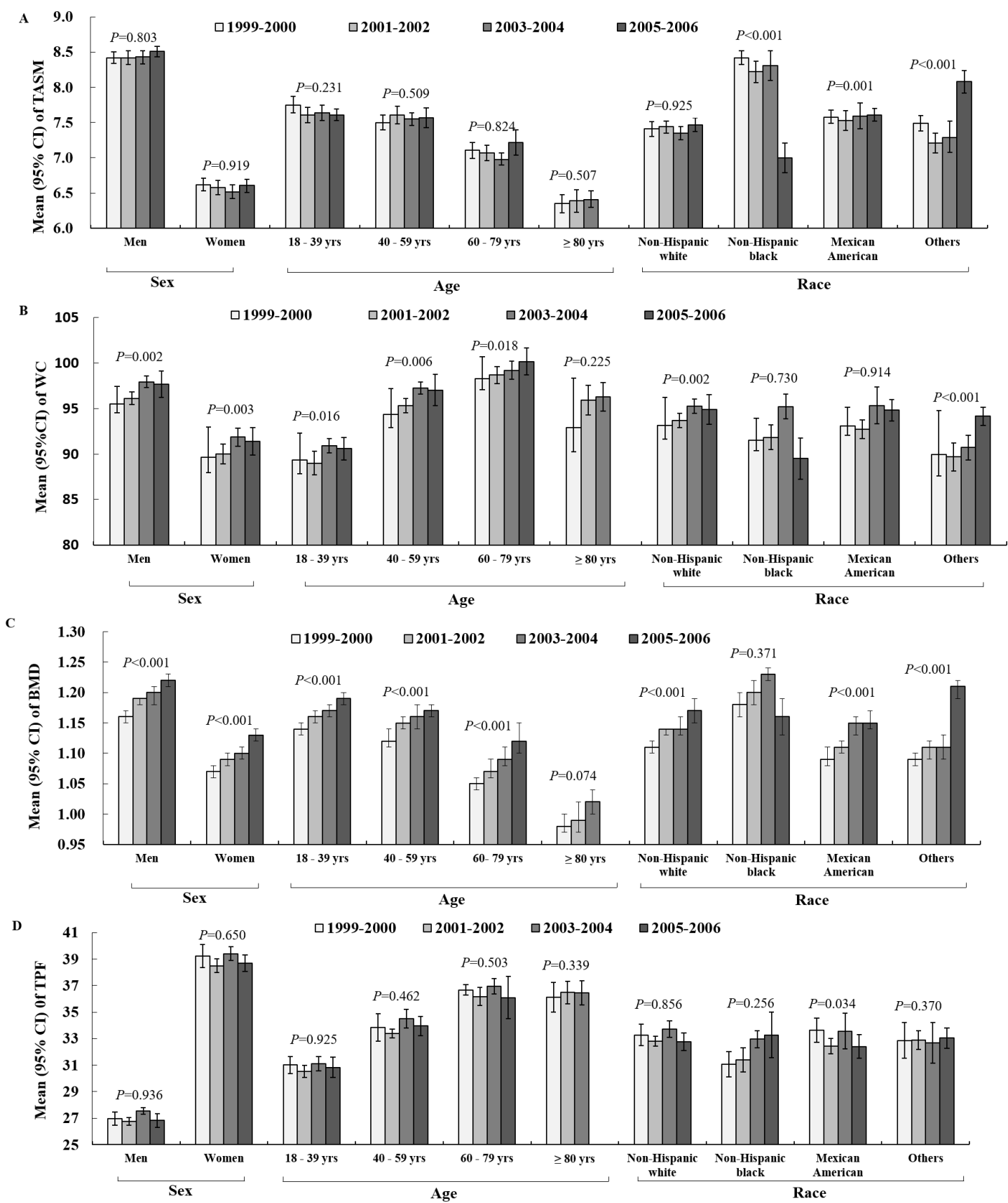

Figure 2 Distribution of body composition measurements, including SMI (A), WC (B), BMD (C) and TPF (D), by sex, age and racial group from 1999 to $2006.95 \% \mathrm{Cl}$. P values refer to temporal trends obtained by logistic regression models after adjusting for sex, age, race, education level, annual household income, time spent watching TV per day and physical activity level. BMD, bone mineral density; SMI, Skeletal Muscle Index; TASM, total appendicular skeletal muscle; TPF, total percentage of body fat; TV, television; WC, waist circumstance.

period of muscle mass and starts to decline at approximately 50 years of age. ${ }^{39}$ The speed of muscle strength decline is $2-5$ times faster than that of muscle mass over the same period. ${ }^{40}$

We found that the prevalence of presarcopenia was stable in both genders from 1999 to 2006. It was also found that women had a higher prevalence of pre-sarcopenia than men in 2005-2006. This might be caused by a more rapid decrease in the prevalence of presarcopenia among men than women. Previous evidence, however, is inconsistent. For instance, the study of Iannuzzi-Sucich et al found a higher prevalence of sarcopenia in men than in women who were aged $64-93$ years ${ }^{41}$ while the findings in the Fifth Korea NHANES showed that sarcopenia was more prevalent in women. ${ }^{42}$ Women have less absolute and relative muscle mass than men. ${ }^{43}$ In addition, given the natural differences in skeletal muscle between men and women, such as the amount of muscle mass, muscle capillary density and muscle fibre type, ${ }^{44}$ physical activity might be a potential cause for sex differences in the prevalence of sarcopenia. ${ }^{45}$ In our study, most women had lower self-reported levels of physical activity than men. 
Vigorous physical activity in men gradually increased, whereas it decreased in women over time. Another critical factor is age-related changes in gonadal function and sex hormones regulating muscle mass distribution. Evidence suggests that lower serum testosterone levels in elderly men contribute to muscle weakness. ${ }^{46}$ Men experience a gradual decrease in knee extensor and handgrip strength between 20 and 80 years of age, whereas women experience a steep decline after the age of 55 (menopausal age). ${ }^{47}$ Although it is not clear whether age-related changes in gonadal function directly regulate physical activity in humans, gonadectomy has been shown to cause a dramatic decline in spontaneous physical activity in animals. ${ }^{49}$ Thus, sex differences might be pivotal in understanding the process of sarcopenia and ageing, and understanding why each sex remains 'muscle healthy' throughout their lifespan could open new avenues to prevent sarcopenia and the ageing process.

We also detected a considerably increased trend of presarcopenia prevalence in non-Hispanic black people, while the prevalence was stable in non-Hispanic whites and Mexican Americans over time. Racial differences in muscle mass have been reported in previous studies. Evidence has shown that African Americans have a significantly higher skeletal muscle/adipose tissue-free body mass ratio than other races, although the difference was very small. ${ }^{50}$ Mahbubur and Abbey reported that black women had greater levels of total and regional lean mass than white and Hispanic women and that Hispanic women had even lower values than white women in an assessment of the body composition of 708 healthy black, white and Hispanic women aged 16-33years using DXA analysis. ${ }^{51}$ According to the NHANES III bioelectrical impedance data, the amount of fat-free mass in Mexican Americans was lower than that in non-Hispanic Blacks, which was in turn lower than that in non-Hispanic whites. ${ }^{52}$ The underlying mechanism of these racial differences is still unclear and warrants further investigation.

This is a representative population-based study. This is the first study that focused on presarcopenia among adults. However, there are several limitations in this study. First, we only assessed muscle mass data rather than muscle strength, which does not reflect muscle power and may be confounded by a third variable that was not involved in this study. Second, the prevalence of presarcopenia in women may be underestimated because we used a heightadjusted definition of the condition, ${ }^{53}$ which is potentially problematic in identifying participants with sarcopenic obesity. ${ }^{54}$ However, if we had used the weight-adjusted definition, people classified as having pre-sarcopenia would have had higher BMI values compared with those without sarcopenia. ${ }^{55}$ Third, as physical activity data were self-reported, reporting bias may exist. Recent research on self-reported levels of physical activity indicated that individuals in the USA tended to have differing perceptions of activity levels and that compared with Europeans, US individuals overestimate their time spent exercising. ${ }^{56}$ Future studies should apply objective measures to determine muscle strength and physical activity to accurately evaluate sarcopenia prevalence.

\section{CONCLUSIONS}

The overall prevalence of presarcopenia was stable in both men and women from 1999 to 2006 among US adults, while there is a slight increase in the prevalence of presarcopenia from 1999 to 2006 among US young adults. Adults who were non-Hispanic blacks, elderly or under/normal weight are at high risk of presarcopenia. Meanwhile, we found a significant increased trend of obesity, central obesity. It suggests that the high prevalence of presarcopenia and obesity is an important public health concern. It might be helpful to maintain resistant and at least moderate physical activity for the prevention of sarcopenia and obesity in US adults.

Acknowledgements We would like to thank Christopher Lavender for the discussion on the manuscript. We also appreciate the help of Yang Deng for assistance with data collection.

Contributors J-BL, XZ and HL designed and conducted the research; J-BL, XZ and $\mathrm{HL}$ analysed the data; J-BL, XZ, HL, YW and DG were responsible for the final content of the manuscript; all authors took part in writing the manuscript and read and approved the final version.

Funding This work was supported by NSFC (Natural Science Foundation of China, no: 81703238) (XZ, YW and DG).

Patient consent for publication Not required.

Ethics approval All NHANES protocols were approved by the National Centre for Health Statistics Research ethics review board.

Provenance and peer review Not commissioned; externally peer reviewed.

Data availability statement Data are available in a public, open access repository. The data link is https://www.cdc.gov/nchs/nhanes/index.htm.

Open access This is an open access article distributed in accordance with the Creative Commons Attribution Non Commercial (CC BY-NC 4.0) license, which permits others to distribute, remix, adapt, build upon this work non-commercially, and license their derivative works on different terms, provided the original work is properly cited, appropriate credit is given, any changes made indicated, and the use is non-commercial. See: http://creativecommons.org/licenses/by-nc/4.0/.

ORCID iDs

Ji-Bin Li http://orcid.org/0000-0001-7632-3648

Xi Zhang http://orcid.org/0000-0002-4524-2084

\section{REFERENCES}

1 Cruz-Jentoft AJ, Baeyens JP, Bauer JM, et al. Sarcopenia: European consensus on definition and diagnosis: report of the European working group on sarcopenia in older people. Age Ageing 2010;39:412-23.

2 Trajanoska K, Schoufour JD, Darweesh SK, et al. Sarcopenia and its clinical correlates in the general population: the Rotterdam study. $J$ Bone Miner Res 2018;33:1209-18.

3 Santilli V, Bernetti A, Mangone M, et al. Clinical definition of sarcopenia. Clin Cases Miner Bone Metab 2014;11:177-80.

4 Provan M, Mander T. Mobility, exercise, nutrition and healthy ageing to avoid sarcopenia. Post Reprod Health 2018;24:98-102.

5 Lynch GS, Koopman R. Dietary meat and protection against sarcopenia. Meat Sci 2018;144:180-5.

6 Lee S-G, Lee Y-h, Kim KJ, et al. Additive association of vitamin D insufficiency and sarcopenia with low femoral bone mineral density in noninstitutionalized elderly population: the Korea National health and nutrition examination surveys 2009-2010. Osteoporos Int 2013;24:2789-99.

7 Wakabayashi H, Sakuma K. Comprehensive approach to sarcopenia treatment. Curr Clin Pharmacol 2014;9:171-80. 
8 Fry CS, Lee JD, Mula J, et al. Inducible depletion of satellite cells in adult, sedentary mice impairs muscle regenerative capacity without affecting sarcopenia. Nat Med 2015;21:76-80.

9 Campos F, Abrigo J, Aguirre F, et al. Sarcopenia in a mice model of chronic liver disease: role of the ubiquitin-proteasome system and oxidative stress. Pflugers Arch - Eur J Physiol 2018;470:1503-19.

10 Roubenoff R. Sarcopenic obesity: does muscle loss cause fat gain? lessons from rheumatoid arthritis and osteoarthritis. Ann NY Acad Sci 2000;904:553-7.

11 Chen Y-C, Tu Y-K, Huang K-C, et al. Pathway from central obesity to childhood asthma. Physical fitness and sedentary time are leading factors. Am J Respir Crit Care Med 2014;189:1194-203.

12 Calvani R, Marini F, Cesari M, et al. Biomarkers for physical frailty and sarcopenia: state of the science and future developments. $J$ Cachexia Sarcopenia Muscle 2015;6:278-86.

13 Kim SE. Clinical implication of sarcopenia in patients with inflammatory bowel disease. Korean J Gastroenterol 2018;71:308-14.

14 Ryan E, McNicholas D, Creavin B, et al. Sarcopenia and inflammatory bowel disease: a systematic review. Inflamm Bowel Dis 2019;25:67-73

15 Han E, Lee Y-H, Kim BK, et al. Sarcopenia is associated with the risk of significant liver fibrosis in metabolically unhealthy subjects with chronic hepatitis B. Aliment Pharmacol Ther 2018;48:300-12.

16 Hanai T, Shiraki M, Nishimura K, et al. Sarcopenia impairs prognosis of patients with liver cirrhosis. Nutrition 2015;31:193-9.

17 Moctezuma-Velázquez C, Low G, Mourtzakis M, et al. Association between low testosterone levels and sarcopenia in cirrhosis: a crosssectional study. Ann Hepatol 2018;17:615-23.

18 Bhanji RA, Moctezuma-Velazquez C, Duarte-Rojo A, et al. Myosteatosis and sarcopenia are associated with hepatic encephalopathy in patients with cirrhosis. Hepatol Int 2018;12:377-86.

19 Siegert E, March C, Otten L, et al. Prevalence of sarcopenia in systemic sclerosis: assessing body composition and functional disability in patients with systemic sclerosis. Nutrition $2018 ; 55-$ 56:51-5.

20 Miyamoto Y, Baba Y, Sakamoto Y, et al. Sarcopenia is a negative prognostic factor after curative resection of colorectal cancer. Ann Surg Oncol 2015;22:2663-8.

21 Voron T, Tselikas L, Pietrasz D, et al. Sarcopenia impacts on shortand long-term results of hepatectomy for hepatocellular carcinoma. Ann Surg 2015;261:1173-83.

22 Joglekar S, Asghar A, Mott SL, et al. Sarcopenia is an independent predictor of complications following pancreatectomy for adenocarcinoma. J Surg Oncol 2015;111:771-5.

23 Jones SE, Maddocks M, Kon SSC, et al. Sarcopenia in COPD: prevalence, clinical correlates and response to pulmonary rehabilitation. Thorax 2015;70:213-8.

24 Chin SO, Rhee SY, Chon S, et al. Sarcopenia is independently associated with cardiovascular disease in older Korean adults: the Korea National health and nutrition examination survey (KNHANES) from 2009. PLoS One 2013;8:e60119.

25 Atkins JL, Whincup PH, Morris RW, et al. Sarcopenic obesity and risk of cardiovascular disease and mortality: a population-based cohort study of older men. J Am Geriatr Soc 2014;62:253-60.

$26 \mathrm{Kim}$ YK, Lee HS, Ryu JJ, et al. Sarcopenia increases the risk for mortality in patients who undergo amputation for diabetic foot. $J$ Foot Ankle Res 2018;11:32.

27 Plan and operation of the third National health and nutrition examination survey, 1988-94. series 1: programs and collection procedures. Vital Health Stat 1 1994;32:1-407.

28 Flegal KM, Carroll MD, Kit BK, et al. Prevalence of obesity and trends in the distribution of body mass index among US adults, 1999-2010. JAMA 2012;307:491-7.

29 World Health Organization. Obesity: preventing and managing the global epidemic. Report of a who consultation. World Health Organ Tech Rep Ser 2000;894:253.

30 Cruz-Jentoft AJ, Baeyens JP, Bauer JM, et al. Sarcopenia: European consensus on definition and diagnosis: report of the European Working group on sarcopenia in older people. Age Ageing 2010;39:412-23.

31 Menke A, Casagrande S, Geiss L, et al. Prevalence of and trends in diabetes among adults in the United States, 1988-2012. JAMA 2015;314:1021-9.
32 Flegal KM, Carroll MD, Ogden CL, et al. Prevalence and trends in obesity among US adults, 1999-2008. JAMA 2010;303:235-41.

33 Wannamethee SG, Atkins JL. Muscle loss and obesity: the health implications of sarcopenia and sarcopenic obesity. Proc Nutr Soc 2015;74:405-12.

34 Cleasby ME, Jamieson PM, Atherton PJ. Insulin resistance and sarcopenia: mechanistic links between common co-morbidities. J Endocrinol 2016;229:R67-81.

35 Janssen I, Heymsfield SB, Wang ZM, et al. Skeletal muscle mass and distribution in 468 men and women aged 18-88 yr. J Appl Physiol 2000;89:81-8.

36 Newman AB, Haggerty CL, Goodpaster B, et al. Strength and muscle quality in a well-functioning cohort of older adults: the health, aging and body composition study. J Am Geriatr Soc 2003;51:323-30.

37 Rolland Y, Czerwinski S, Abellan Van Kan G, et al. Sarcopenia: its assessment, etiology, pathogenesis, consequences and future perspectives. J Nutr Health Aging 2008;12:433-50.

38 Goodpaster BH, Park SW, Harris TB, et al. The loss of skeletal muscle strength, mass, and quality in older adults: the health, aging and body composition study. J Gerontol A Biol Sci Med Sci 2006;61:1059-64.

39 Silva AM, Shen W, Heo M, et al. Ethnicity-related skeletal muscle differences across the lifespan. Am J Hum Biol 2010;22:76-82.

40 Delmonico MJ, Harris TB, Visser M, et al. Longitudinal study of muscle strength, quality, and adipose tissue infiltration. Am J Clin Nutr 2009:90:1579-85.

41 lannuzzi-Sucich M, Prestwood KM, Kenny AM. Prevalence of sarcopenia and predictors of skeletal muscle mass in healthy, older men and women. J Gerontol A Biol Sci Med Sci 2002;57:M772-7.

42 Hong N, Lee EY, Kim CO. Gamma-Glutamyl transferase is associated with sarcopenia and sarcopenic obesity in community-dwelling older adults: results from the fifth Korea National health and nutrition examination survey, 2010-2011. Endocr J 2015;62:585-92.

43 Marcellino C, Henn RL, Olinto MT, et al. Physical inactivity and associated factors among women from a municipality in southern Brazil. J Phys Act Health 2014;11:777-83.

$44 \mathrm{Kim}$ J. Gender difference in association between appendicular skeletal muscle mass and cardiometabolic abnormalities in normalweight and obese adults: Korea National health and nutrition examination survey (KNHANES) IV-3 and V-1. Asia Pac J Public Health 2015;27:NP468-75.

45 Genton L, Karsegard VL, Chevalley T, et al. Body composition changes over 9 years in healthy elderly subjects and impact of physical activity. Clin Nutr 2011;30:436-42.

46 Doherty TJ. Invited review: aging and sarcopenia. J Appl Physiol 2003;95:1717-27.

47 Samson MM, Meeuwsen IB, Crowe A, et al. Relationships between physical performance measures, age, height and body weight in healthy adults. Age Ageing 2000;29:235-42.

48 Phillips SK, Rook KM, Siddle NC, et al. Muscle weakness in women occurs at an earlier age than in men, but strength is preserved by hormone replacement therapy. Clin Sci 1993;84:95-8.

49 Rosenfeld CS. Sex-dependent differences in voluntary physical activity. J Neurosci Res 2017;95:279-90.

50 Wang Z, Heo M, Lee RC, et al. Muscularity in adult humans: proportion of adipose tissue-free body mass as skeletal muscle. Am J Hum Biol 2001;13:612-9.

51 Rahman M, Berenson AB. Racial difference in lean mass distribution among reproductive-aged women. Ethn Dis 2010;20:346-52.

52 Chumlea WC, Guo SS, Kuczmarski RJ, et al. Body composition estimates from NHANES III bioelectrical impedance data. Int J Obes Relat Metab Disord 2002;26:1596-609.

53 Meng N-H, Li C-I, Liu C-S, et al. Comparison of height- and weightadjusted sarcopenia in a Taiwanese metropolitan older population. Geriatr Gerontol Int 2015;15:45-53.

54 Kim Y-S, Lee Y, Chung Y-S, et al. Prevalence of sarcopenia and sarcopenic obesity in the Korean population based on the fourth Korean National health and nutritional examination surveys. $J$ Gerontol A Biol Sci Med Sci 2012;67:1107-13.

55 Janssen I, Heymsfield SB, Ross R. Low relative skeletal muscle mass (sarcopenia) in older persons is associated with functional impairment and physical disability. J Am Geriatr Soc 2002;50:889-96.

56 Kapteyn A, Banks J, Hamer M, et al. What they say and what they do: comparing physical activity across the USA, England and the Netherlands. J Epidemiol Community Health 2018;72:471-6. 